\title{
Vitamin D Deficiency in South Sharqiya in Oman and its Impact on ENT Patients - A Retrospective Study
}

\author{
Hasan Abdul Cader Segana, ${ }^{1}$ Reghunandanan Nair, ${ }^{1}$ Fahim Ahmed Shah ${ }^{1}$
}

\section{Introduction}

\section{$\underline{\text { ABSTRACT }}$}

Vitamin D deficiency has multitude of causes and can present with varying clinical manifestations. Studies show that it can lead on to recurrent respiratory infections, ear infections and deafness. Vitamin D also has immunomodulant action. Here we discuss the varying features concerning an Otolaryngologist in general as far as Vitamin D metabolism is concerned.

\section{Materials and Methods}

This retrospective study was performed on 800 patients 152 males and 648 females of different socioeconomic background at secondary level regional referral hospital under Ministry of Health in Sultanate of Oman. The patients attending the outpatient clinic with various complaints and not responding to conventional treatment were advised for assessment of vitamin D [25 $(\mathrm{OH}) \mathrm{D}]$ level in blood. The patients were evaluated with general history, blood samples of serum calcium, phosphate, alkaline phosphatase and serum vitamin D level were measured by the most standardized laboratory of the country.

\section{$\underline{\text { Results }}$}

Out of 800 patients, 275 cases had Vitamin D levels below $20 \mathrm{ng} / \mathrm{ml}$ and 167 patients had values greater than $30 \mathrm{ng} / \mathrm{ml}$ in serum. $81 \%$ patients with vitamin D deficiency were females. $56.25 \%$ patients were between third and sixth decade. Otolaryngologic manifestations were acute and recurrent URTI $(n=352) 44 \% .7 \%$ of the patients presented with recurrent ear infection (otitis externa). The rest of them presented to a lesser extent with deafness, otosclerosis.

\section{Discussion}

Vitamin $D$ deficiency has been reported worldwide as one of the commonest deficiency diseases. It can lead to autoimmune dysfunctions, Beta cell dysfunction in pancreas, Multiple sclerosis, recurrent chest infections and congestive cardiac failure. Studies have shown the involvement of cochlea with sensorineural hearing loss and otosclerosis.

\section{$\underline{\text { Conclusion }}$}

Vitamin $D$ deficiency has multi system implications as patients presenting with different signs and symptoms. Mass level screening and vitamin D supplementation should be planned to decrease its varied and multidimensional ill effects on health. Adequate vitamin D supplementation and sensible sunlight exposure to reach optimal vitamin D status are among the front line factors of prophylaxis for spectrum of disorders.

$\underline{\text { Keywords }}$

Vitamin D Deficiency; Prevalence; Oman; Diagnosis; Deafness

$\mathrm{V}$ itamin D is considered an essential micronutrient. It is well known for its important role, together with calcium, in bone mineralization. Vitamin D in human body is present in several forms: the most important are 1,25-hydroxyvitamin $\mathrm{D}$, the circulating form, and 1,25- dihydroxyvitamin $\mathrm{D}$, the

1 - Department of ENT, Sur Hospital, Oman

\section{Corresponding author:}

Dr Hasan Abdul Cader Segana

email: dr_shac@yahoo.com active form. Vitamin D is produced in the skin through exposure to UV light $^{1}$ (through the transformation of 7-dehydrocholesterol in vitamin D3 or cholecalciferol) or absorbed from few foods. Vitamin D can be ingested in the form of vitamin D3 or vitamin D2 (ergocalciferol).

Vitamin D is important for good health, growth and strong bones. A lack of vitamin D is very common. Vitamin D is mostly made in the skin by exposure to sunlight. Most foods contain very little vitamin D naturally. Some people are more at risk of vitamin D deficiency, and so are recommended to take vitamin D 
supplements routinely. These include all pregnant and breastfeeding women, all infants and young children aged 6 months to 5 years, people aged 65 and over, and people who are not exposed much to sun.

Vitamin D deficiency can also occur in people taking certain medicines, Examples include: Carbamazepine, Phenytoin, Primidone, Barbiturates and some anti-HIV medicines. Most affected people either don't have any symptoms, or have tiredness or vague aches and pains, or are unaware of the problem. Many studies suggest that vitamin D deficiency can lead on to recurrent respiratory and ear infections. ${ }^{2}$ A simple blood test for vitamin $\mathrm{D}$ level can make the diagnosis.

Vitamin D, in its active form 1,25-hydroxyvitamin $\mathrm{D}$, has a complex action on the immune system, by modulating and inhibiting its activity in different ways. Pathogenic microorganism sensing by the Toll-like receptor 2/1 (TLR2/1) complex increases expression of vitamin D receptors (VDR) and CYP27B1 in monocytes. $^{3}$ The synthesis of 1,25-dihydroxyvitamin D promotes VDR-mediated transactivation of the antimicrobial peptide cathelicidin and killing of intracellular microbes.

Cathelicidins have a direct antimicrobial function. In addition to anti-bacterial effects including membrane disruption, they have antiviral effect in the inhibition of herpes simplex viruses, adenovirus and retrovirus. ${ }^{4}$ A study showed that transcriptional regulation of cathelicidin can be mediated by activation of 1,25-dihydroxivitamin D. Stimulation of TLR receptors in macrophages by microbial products results in increased conversion from the inactive 25 -hydroxyvitamin $\mathrm{D}$ to the active 1,25-hydroxyvitamin D. According to Adams and colleagues, a consequence of TLR activation is the production of defensin- 2 and of cathelicidin: these two antimicrobical peptides are strongly up-regulated by 1,25-hydroxyvitamin D. ${ }^{5}$ A research has documented that 1,25-dihydroxyvitamin $\mathrm{D}$ promotes autophagy in monocytes. ${ }^{6}$

In the Middle East and other Arab countries, the hypovitaminosis D is very frequent in children and adults. A cross-sectional study observed high prevalence of vitamin D deficiency (VDD) in apparently healthy children living in Jeddah. ${ }^{7}$ For cultural and religious reasons, the dress style of women outdoors prevents exposure of skin to sunlight. A cross-sectional randomized study conducted in Saudi Arabia indicated that VDD among healthy Saudi women of 25-35 years was $30 \%$ and $55 \%$ in women of $\geq 50$ years. ${ }^{8}$ In Iran high percentage of VDD was defined in a population study: in Teheran prevalence of severe, moderate and mild VDD was $9.5 \%, 57.6 \%$ and $14.2 \%$ respectively. ${ }^{9}$ New lifestyles, with an increase in time spent in artificial environment (offices, houses, commercial centres), mainly in the hottest season, limit the physiological ability of human body to synthesize from precursor "active" form of vitamin D.

Much debate has taken place over the definition of vitamin D deficiency. Most agree that a $25(\mathrm{OH})$ D concentration $\leq 50 \mathrm{nmol} / \mathrm{L}$, or $20 \mathrm{ng} / \mathrm{mL}$, is an indication of vitamin D deficiency, whereas a $25(\mathrm{OH})$ D concentration of $51-74 \mathrm{nmol} / \mathrm{L}$, or $21-29 \mathrm{ng} / \mathrm{mL}$, is considered to indicate insufficiency; concentrations $>30 \mathrm{ng} / \mathrm{mL}$ are considered to be sufficient. ${ }^{10}$

Vitamin D deficiency increases patients' vulnerability to viral respiratory infections and it is also involved in the pathophysiology of chronic rhinitis and rhinosinusitis. ${ }^{11}$

Researches have shown that VDD is associated with development of vertigo. In fact, scientists have confirmed that Vitamin D receptors are located on calcium channel transport systems in the inner ear and help regulate proper calcium balance. This mechanism helps explain the role of vitamin $\mathrm{D}$ in maintaining proper ear function. The role of vitamin $\mathrm{D}$ deficiency has been attributed to cochlear deafness, Meniere's disease and otosclerosis including cochlear otosclerosis representing with trough shaped pure tone audiogram with a dip during 1 and $2 \mathrm{kHz}$ frequencies. ${ }^{12}$ The calcium and phosphorus content of the woven bone of the otic capsule are much higher than other bones hence may be more affected by deficient vitamin D levels. ${ }^{13}$

\section{Materials and Methods}

The study was performed on 800 patients 152 males and 648 females of different socioeconomic background. This was a retrospective study performed over a ten 
year period from 2005 to 2015 at Sur Hospital in South Sharqiyah region of Oman. The patients were attending the general medical outpatient department, and were referred from other hospitals and clinics attached to Sur Hospital. The patients attending outpatient of medical clinic with various complaints and not responding to conventional treatment were advised for assessment of vitamin D [25 $(\mathrm{OH}) \mathrm{D}]$ level in blood. Those presenting with ENT symptoms were referred to Outpatient ENT clinic. A quick general history and examination was also undertaken for presence of other medical conditions. The age groups ranged from 20 to 80 years, mean age being 50 years. Subjects were predominantly married and majority living in their houses or offices and when outdoor most of them only exposed face and hands. Blood samples were collected in the morning. Overnight fasting sample was collected by venepuncture by disposable syringes and $5 \mathrm{ml}$ blood sample was taken and samples were stored at $-20^{\circ} \mathrm{C}$ till they were analyzed in the laboratory. Their serum calcium, phosphate, alkaline phosphatase and serum vitamin D level were measured by the most standardized laboratory of the country. The study was analyzed on SPSS-Version-16 for windows. $\mathrm{P}<0.05$ was considered statistically significant. In our study the various determinants and variables of interest were: age, gender, serum calcium, phosphate, alkaline phosphatase, serum vitamin D levels and history of bone or body aches.

\section{Results}

Vitamin D deficiency is defined as serum $25(\mathrm{OH}) \mathrm{D}$ level below $20 \mathrm{ng} / \mathrm{mL}$ and out of 800 patients, Vitamin $\mathrm{D}$ deficiency was found in $34.3 \%(\mathrm{n}=275)$ of patients. Comparing this to serum $25(\mathrm{OH}) \mathrm{D}$ level that was sufficient at greater than $30 \mathrm{ng} / \mathrm{mL}$, we found among our 800 patients that this was evident among $21 \%$ $(n=167)$. (Fig. 1) Overall 79.0\% $(n=733)$ of the study population had sub-optimal levels of Vitamin $\mathrm{D}(<30 \mathrm{ng} /$ $\mathrm{mL}) .800$ patients were reviewed for this retrospective chart analysis. Males comprised $19 \%(\mathrm{n}=152)$ and $81 \%$ $(\mathrm{n}=648)$ were females.

The number of patients below the age of 30 years was $181(22.62 \%)$ and 158 of them (87.2\%) had sub-optimal levels of vitamin D. Four hundred and fifty (450) patients $(56.25 \%)$ were of the age between $30-60$ years and 373 $(82.8 \%)$ of them had sub-optimal vitamin D whereas 169 patients $(21.12 \%)$ were above 60 years and 102 of them $(60.3 \%)$ had sub-optimal levels of vitamin D. (Fig. 2, Table I) Analysis on the basis of gender concluded that $61 \%(n=93)$ of total males and $83.3 \%(n=540)$ of total females had a deficient serum Vit.D. We also found that 119 patients were obese and 99 patients $(92 \%)$ had sub-optimal level of vitamin D. Only 185 patients $(30.83 \%)$ were having bone or body aches as a presenting feature while remaining 415 individuals $(69.16 \%)$ were having no pains. In our sample, all had normal values for serum Calcium and Phosphates. However, only 20 patients had modestly elevated levels of serum alkaline phosphatase.

Most of the patient who attended the ENT clinic, presented with acute and recurrent URTI ( $\mathrm{n}=352 ; 44 \%)$. Seven per cent of the patients presented with recurrent ear infection (otitis externa). The rest of them presented to a lesser extent with deafness, otosclerosis.(Table II) Out of the 800 patients, 633 patients $(79.1 \%)$ required Vit. D supplementation.(Table III)

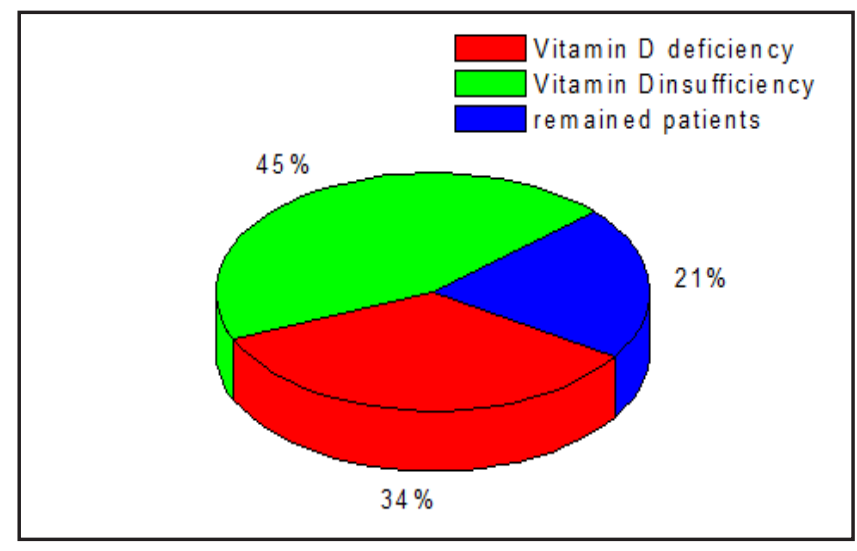

Fig.1. Total No. of Vit. D insufficiency and deficiency in 800 medical patients

\section{Discussion}

Vitamin D deficiency is common disease in the world. It has been widely reported in all age groups in recent years. Rickets has never been eradicated in developed countries as well. ${ }^{14}$ Hypo-vitaminosis and Vitamin D 
Table I : The incidence of Vitamin D deficiency and insufficiency in different age groups

\begin{tabular}{|c|c|c|c|c|c|}
\hline 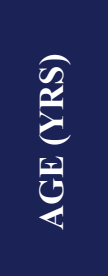 & $\stackrel{\frac{8}{6}}{\frac{8}{6}}$ & 章 & 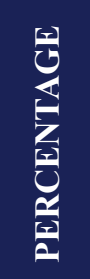 & 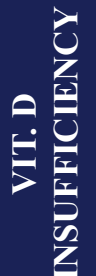 & 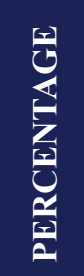 \\
\hline$<30$ & 181 & 100 & $55 \%$ & 58 & $32 \%$ \\
\hline $30-60$ & 450 & 151 & $33 \%$ & 222 & $49 \%$ \\
\hline$>60$ & 169 & 24 & $14 \%$ & 78 & $36 \%$ \\
\hline
\end{tabular}

deficiency have been in developed and developing countries including several in the Middle East.15 Vitamin D is important for calcium absorption and bone growth. ${ }^{15}$ Vitamin D inadequacy is a causative factor in development of certain autoimmune diseases ${ }^{14,16,17}$ like

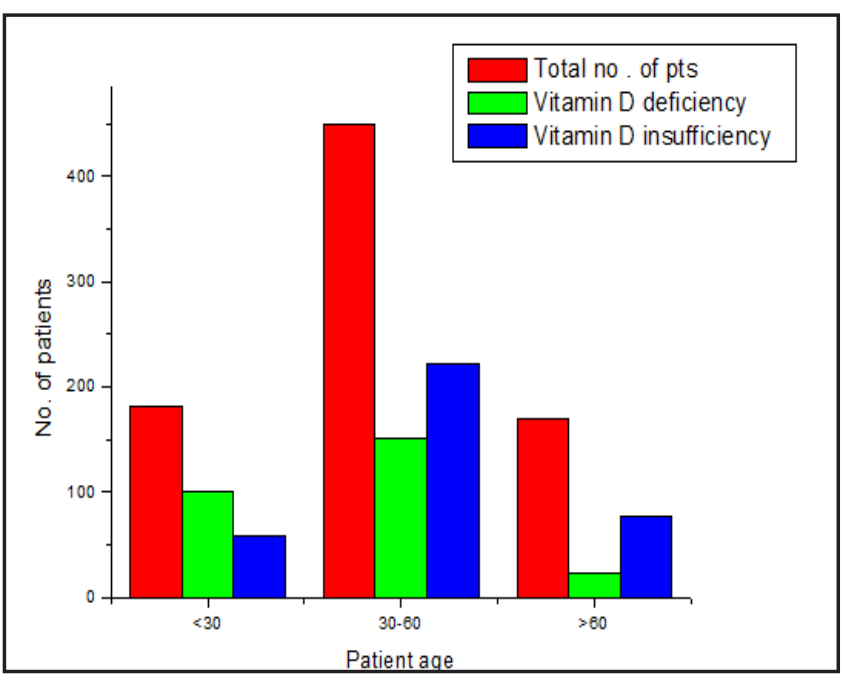

Fig.2. The incidence of Vit. D deficiency and insufficiency in different age groups

type 1 diabetes, ${ }^{16,17}$ rheumatoid arthritis and certain cancers later in life. ${ }^{14}$

Vitamin D deficiency exists in patients with tuberculosis and it is possibly a cause rather than effect of the disease. ${ }^{18}$ It is part of the pathology of Alzheimer's, Parkinson's and some peripheral neuropathies including Restless legs syndrome. ${ }^{19}$ Vitamin D deficiency may also
Table II: Presenting clinical features of patient with Vit. D deficiency

\begin{tabular}{|c|c|c|c|}
\hline $\begin{array}{l}\theta \\
\ddot{Z} \\
\dot{\sigma} \\
\dot{\sigma}\end{array}$ & 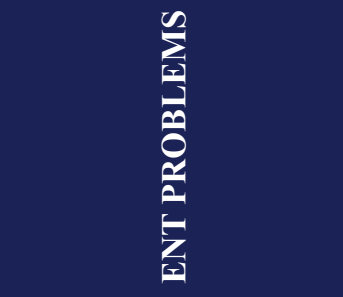 & 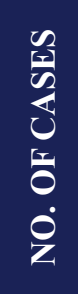 & 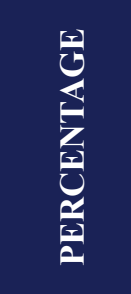 \\
\hline 1 & Recurrent URTI & 352 & $44 \%$ \\
\hline 2 & Sinusitis & 92 & $11.5 \%$ \\
\hline 3 & $\begin{array}{l}\text { Pharyngitis }+ \\
\text { Tonsillitis }\end{array}$ & 90 & $11.25 \%$ \\
\hline 4 & $\begin{array}{c}\text { Chronic headache } \\
\text { and fatigue }\end{array}$ & 24 & $3 \%$ \\
\hline 5 & $\begin{array}{c}\text { Simple } \\
\text { Vertigo(unsteadiness) }\end{array}$ & 34 & $4.25 \%$ \\
\hline 6 & $\begin{array}{l}\text { Recurrent ear } \\
\text { infection }\end{array}$ & 56 & $7 \%$ \\
\hline 7 & $\begin{array}{c}\text { CSOM } \\
\text { Tubotympanic type }\end{array}$ & 12 & $1.5 \%$ \\
\hline 8 & $\begin{array}{c}\text { CSOM Atticoantral } \\
\text { type }\end{array}$ & 10 & $1.25 \%$ \\
\hline 9 & Otosclerosis & 6 & $0.75 \%$ \\
\hline 10 & $\begin{array}{c}\text { Sensorineural } \\
\text { deafness }\end{array}$ & 15 & $1.87 \%$ \\
\hline 11 & $\begin{array}{l}\text { Conductive hearing } \\
\text { loss }\end{array}$ & 18 & $2.25 \%$ \\
\hline 12 & BPPV & 14 & $1.75 \%$ \\
\hline 13 & $\begin{array}{c}\text { Airway } \\
\text { Hyperreactivity }\end{array}$ & 19 & $2.37 \%$ \\
\hline 14 & Oral ulcers & 24 & $3 \%$ \\
\hline 15 & $\begin{array}{c}\text { Retracted Ear drums } \\
+ \text { OME }\end{array}$ & 34 & $4.25 \%$ \\
\hline
\end{tabular}

be linked to an increased susceptibility to several chronic diseases such as high blood pressure, ${ }^{20}$ periodontal disease, multiple sclerosis ${ }^{21}$ chronic pain, depression, 
Table III : Total number of patients who required Vit. D supplement

\begin{tabular}{|c|c|c|c|c|}
\hline & & 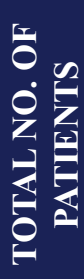 & 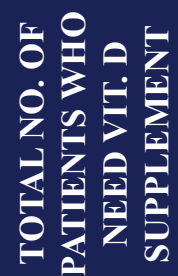 & $\frac{\sqrt[c]{0}}{0}$ \\
\hline \multirow{3}{*}{ 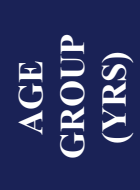 } & $<30$ & 181 & 158 & $87.2 \%$ \\
\hline & $30-60$ & 450 & 373 & $82.8 \%$ \\
\hline & $>60$ & 169 & 102 & $60.3 \%$ \\
\hline \multirow{2}{*}{$\underset{0}{\frac{0}{6}}$} & Male & 152 & 93 & $61 \%$ \\
\hline & Female & 648 & 540 & $83.3 \%$ \\
\hline$\frac{1}{6}$ & & 800 & 633 & $79.1 \%$ \\
\hline
\end{tabular}

schizophrenia, seasonal affective disorder, peripheral artery disease. ${ }^{19}$ Risk of Myocardial Infarction (MI) doubles in patients with $25 \mathrm{OH}$ Vitamin D levels $<34 \mathrm{ng} /$ ml. Studies have shown that Congestive Heart Failure patients have much lower $25 \mathrm{OH}$ Vitamin D levels than controls. ${ }^{22,23}$ Highest Vitamin D levels associated with $60 \%$ improvement in insulin sensitivity. ${ }^{14}$

A study showed that $48 \%$ of patients with Multiple Sclerosis (MS) were found to be havening vitamin D deficiency.22 Risk of Myocardial Infarction (MI) doubles in patients with $25 \mathrm{OH}$ Vitamin D levels $<34 \mathrm{ng} /$ ml. Studies have shown that Congestive Heart Failure patients have much lower $25 \mathrm{OH}$ Vitamin D levels than controls. ${ }^{22,23}$ Low Vitamin D level has association with insulin resistance and Beta cell dysfunction. Highest Vitamin D levels associated with $60 \%$ improvement in insulin sensitivity. ${ }^{14}$ A study showed that $48 \%$ of patients with Multiple Sclerosis (MS) were found to be havening vitamin $\mathrm{D}$ deficiency. ${ }^{24}$ This study was conducted to determine the prevalence of vitamin D deficiency in outpatients clinic, its relation to presenting symptom of bones or body aches and to the serum level of calcium, phosphate and alkaline phosphates. The study showed significantly high prevalence $(79 \%)$ of vitamin D deficiency (34.3\% deficient and $44.7 \%$ were having insufficient levels).

There is wide variation in the existing international data on Vit. D deficiency, showing $14.5 \%$ in U.K reaching to more than $30 \%$ in age above 65 years, $24.3 \%$ in United States, $12.5 \%$ in Italy , $55 \%$ in Irish females $20 \%$ and $83 \%$ in Saudi Arabia. ${ }^{25}$ Possible factors may be due to decreased intake or lack of sun exposure due to social, cultural or religious reasons. ${ }^{26}$ The results of the present study were different from the mentioned international data. There were only 169 $(21.12 \%)$ patients above age 60 year. The remaining $631(78.16 \%)$ patients were below 60 year of age and this difference perhaps may be attributed to fact that majority of sample presented in the clinic was from below 60 year age group. Vitamin D deficiency can occur without any symptoms. If symptoms are present, it indicates severe deficiency. ${ }^{19}$ Similar observations were made in this study, only $31 \%$ patients were having bones or body aches on presentation while remaining $69 \%$ were having no complains showing insignificant relation between deficiency and symptoms $(\mathrm{P}>0.05)$. Hence, the concept that musculoskeletal pain are directly associated with vitamin D deficiency ${ }^{26}$ is not matched to the results of this study. However, young deficient patients were having lesser chance of having bones or body aches as compared to the above 60 year population (P-value $<0.05$ ).

In international literature, Vit. D deficiency has no relation to the serum calcium, phosphate and alkaline phosphates levels. ${ }^{19}$ In our study all the vitamin D deficient population was having normal serum calcium and alkaline phosphates. All this discussion endorses the fact that vitamin $\mathrm{D}$ is much more prevalent in this part of the world. Ear bone remodeling in osteoporosis is similar to the changes in otosclerosis, according to some researchers, osteopenia and osteoporosis may well be associated with idiopathic BPPV. ${ }^{27}$ Ikeda et al (1989) investigated the possible role of vitamin D in hearing impairment by the measurement of three metabolites of vitamin D in 28 patients with bilateral sensorineural hearing loss (BSNHL). Twenty-three 
of 28 patients showed a significantly decreased level of 1,25-dihydroxyvitamin D3, with a normal value of 25-hydroxyvitamin D3. In addition to experimental and clinical reports regarding vitamin D deficiency, in this study it is suggested that vitamin D deficiency is one of the etiologies of BSNHL, through the calcium metabolism and microcirculation in the cochlea. ${ }^{28}$

\section{Conclusion}

Vitamin D deficiency is much more prevalent in our community as compared to published Western data, particularly young population is more suffering to this new endemic, more ever often it is asymptomatic and also serum calcium, phosphate and alkaline phosphates levels are not predictable indicator of its underlying deficiency. It is suggested that due to its multi system implications patients presenting with different signs and symptoms and where to establish a diagnosis is difficult, serum vitamin D3 levels may be requested. Moreover, to overcome this issue it is recommended that health education be imparted to population and awareness should be created to increase the exposure to sunlight to permissible limits.

Mass level screening and vitamin D supplementation ${ }^{25}$ should be planned to decrease its varied and multidimensional ill effects on health. However, it may be taken as an inspiration to conduct health education and to prevent all the ill effects produced by its deficiency. Vitamin D deficiency and insufficiency as a global health problem is likely to be a risk for wide spectrum of acute and chronic illnesses including hearing loss. Adequate vitamin D status seems to be protective against musculoskeletal disorders (muscle weakness, falls, fractures), infectious diseases, autoimmune diseases, cardiovascular disease, type 1 and type 2 diabetes mellitus, several types of cancer, neurocognitive dysfunction and mental illness, and other diseases, as well as infertility and adverse pregnancy and birth outcomes. Vitamin D deficiency/insufficiency is associated with all-cause mortality. ${ }^{29}$

Adequate vitamin D supplementation and sensible sunlight exposure to reach optimal vitamin D status are among the front line factors of prophylaxis for spectrum of disorders. Supplementation guidance and population strategies for eradication of vitamin D deficiency must be included in the priorities of physicians, medical professionals and healthcare policy-makers.

\section{References}

1. Gigineǐshvili GR, Il'in NI, Suzdal'nitskiǔ RS, Levando VA The use of UV irradiation to correct the immune system and decrease morbidity in athletes [in Russian]. Vopr Kurortol Fizioter Lech Fiz Kult. 1990; May-Jun:30-3

2. Wayse V, Yousafzai A, Mogale K, et al. Association of subclinical vitamin D deficiency with severe acute lower respiratory infection in Indian children under 5 y. Eur J Clin Nutr. 2004; 58:563-7

3. Liu PT, Stenger S, Li H, Wenzel I, et al. Toll-like receptors triggering of a vitamin $\mathrm{D}$ mediated anti-microbical response. Science 2006; 311:1770-3. http://dx.doi.org/10.1126/ science. 1123933

4. Bals R, Wilson JM. Cathelicidins - a family of multifunctional antimicrobical peptides. Cell Mol Life Sci. 2003; 60: 711-20. http://dx.doi.org/10.1007/s00018-003-2186-9

5. Adams JS, Ren S, Liu PT, Chun RF, Lagishetty V, Gombart AF, Borregaard N, Modlin RL, Hewison M. Vitamin D directed rheostatic regulation of monocyte antibacterial responses. J Immunol. 2009; 182:4289-95. http://dx.doi.org/10.4049/ jimmunol.0803736

6. Yuk JM, Shin DM, Lee HM, Yang CS, Jin HS, Kim KK, Lee ZW, Lee SH, Kim JM, Jo EK. Vitamin D induces autophagy in human monocytes/macrophages via cathelcidin. Cell Host Microbe 2009; 6(3):231-43. http://dx.doi.org/10.1016/j. chom.2009.08.004

7. Mansour MMHK, Alhadidi KM. Vitamin D deficiency in children living in Jeddah, Saudi Arabia. Indian J Endocrinol Metab. 2012; 16(2):263-9. http://dx.doi.org/10.4103/22308210.93746

8. Al-Turki H, Sadat-Ali M, Al-Elq AH, Al-Mulhim FA, AlAli AK. 25-Hydoxyvitamin D levels among healthy Saudi Arabian women. Saudi Med J. 2008; 29(12):1765-8

9. Hashemipour S, Larijani B, Adibi H, Javadi E, Sedaghat M, Pajouhi M, Soltani A, Shafaei AR, Hamidi Z, Khalili Fard AR, Hossein-Nezhad A, Booya F. Vitamin D deficiency and causative factors in the population of Tehran. BMCPublicHealth 2004; 4:38. http://dx.doi.org/10.1186/1471-2458-4-38

10. Holick MF, Chen TC. Vitamin D deficiency: a worldwide problem with health consequences. Am J Clin Nutr. 2008; 87(Suppl.):1080S-6S

11. Abuzeid WM, Akbar NA, Zacharek MA. Vitamin D and Crhronic Rhinitis. Curr Opin Allergy Clin Immunol. 2012; 
12(1): 13-7. http://dx.doi.org/10.1097/ACI.0b013e32834eccdb

12. Brookes GB. Vitamin D deficiency and deafness: 1984 update Am J Otology 1985; 6(1):102-7

13. Taneja MK. Role of ENT surgeons in the national program for prevention and control of deafness.Indian J otology 2012; 3(18):119-21. doi: 10.4103/0971-7749.103436

14. Kamball S, Fuleihan Gel-H, Vieth R. Vitamin D: a growing perspective. Crit Rev Clin Lab Sci. 2008; 45(4):339-414

15. Pournaghshband $Z$, Amini M. Prevalence of vitamin D deficiency in Isfahani high school students in 2004. Horm Res. 2005 64(3):144-8

16. Travera-M., Luz E., White JH. Cell Defenses and the Sunshine Vitamin. Scientific American, November 2007

17. Holick MF. Sunlight and vitamin D forbone health and prevention ofautoimmune disease, cancers andcardiovascular disease. Am J Clin Nutrition 2004(6): 1678 S-88S

18. Chatfield SM, Brand C., Ebeling PR, Russell DM. Vitamin D deficiency in general medical inpatients in summer and winter. Int Med J. 2007; 37(6):377-82

19. Melamed ML, Muntner P, Michos ED, et al. Serum 25-Hydroxyvitamin D Levels and the Prevalence of Peripheral Arterial Disease. Results from NHANES 2001 to 2004. Arterioscler Thromb Vasc Biol. 2008; 28(6):1179-85. Published online 2008 Apr 16. doi: 10.1161/ATVBAHA.108.165886

20. Anagnostis, P. Athyros, V. G. Adamidou, F. Florentin, M. Karagiannis, A. Vitamin D and cardiovascular disease: a novel agent for reducing cardiovascular risk?. Curr Vasc Pharmacol. 2010 Sep; 8 (5): 720-30

21. Sasidharan PK, Rajeev E, Vijayakumari V. Tuberculosis and vitamin D deficiency.

22. J Assoc Physicians India 2002 Apr; 50:554-8

23. Lau KH, Bayb link DJ. Vitamin D therapy of osteoporosis: plain vitamin $\mathrm{D}$ therapy versus active vitamin $\mathrm{D}$ analog (D hormone) therapy. Calcified Tissue International 1999; 65(4):295-306

24. Scragg R, Jackson R., Holdaway M. Myocardial Infarction is Inversely Associated with Plasma 25-Hydroxyvitamin D3 Levels: A Community-Based Study. Int. J. Epidemiol.1990; 19(3): 559-63

25. Findings presented at the American Society of Clinical Oncology's annual meeting in Chicago on 30 May 2008, as reported in the Sydney Morning Herald on 1 June 2008.

26. Al Faraj S, Al Mutairi K. Vitamin D deficiency and chronic low back pain in Saudi Arabia. Spine 2003; 28(2):177-9

27. Heath KM, Elovic EP. Vitamin D deficiency: Implication in the rehabilitation setting. Am J Phys Med Rehabil. 2006; 85(11): 916-23

28. Jeong SH, Choi SH, Kim JY, Koo JW, Kim HJ, Kim JS. Osteopenia and osteoporosis in idiopathic benign positional vertigo. Neurology 2009; 72(12):1069-76

29. Ikeda K, Kobayashi $T$, Itoh Z, Kusakari J, Takasaka $T$. Evaluation of vitamin D metabolism in patients with bilateral sensorineural hearing loss. Am J Otol.1989;10(1):11-3

30. Hossein-nezhad A, Holick MF. Optimize dietary intake of vitamin D: an epigenetic perspective. Curr Opin Clin Nutr Metab Care 2012; 15(6):567-79. doi: 10.1097/ MCO.0b013e3283594978. 